\title{
Deuda, soberanía y democracia en América Latina
}

\section{LA DEUDA Y LA ESTRATEGIA ORTODOXA}

\section{Imposibilidad de aumentar el superávit comercial}

La deuda externa de los países latinoamericanos no tiene arreglo dentro del ajuste tradicional de los pagos internacionales. Las expresiones en sentido contrario son simples manifestaciones de deseos. Estas revelan la impotencia del actual orden internacional para resolver los problemas fundamentales y, también, las encrucijadas que enfrenta la política económica de los países deudores.

No es posible, en efecto, generar en condiciones aceptables el superávit comercial y de la cuenta corriente del balance de pagos, para pagar los servicios de la deuda. Esta imposibilidad emerge de la convergencia de múltiples factores.

En primer lugar, el monto de la deuda y el nivel de la tasa de interés. El endeudamiento alcanzó proporciones sin precedentes respecto de las variables económicas reales. La deuda externa de América Latina representa, actualmente el $40 \%$ del PBI y 3,4 veces el valor de las exportaciones. A su vez, la tasa de interés deflacionada por el índice de precios de los Estados Unidos, supera el $71 \%$ anual, contra un promedio del $2 \%$ en las últimas tres décadas. La tasa real de interés es aún mayor si el ajuste se realiza por los términos de intercambio de los deudores latinoamericanos no exportadores de petróleo. La tasa real de interés así medida alcanzó al $20 \%$ en 1983. De este modo, los intereses de la deuda han pasado a representar el 35\% de las exportaciones latinoamericanas, en 1983, respecto del $12 \%$ en 1977.

En segundo lugar, la modificación de los precios relativos de la producción exportable no provoca, en las actuales condiciones del mercado mundial, el aumento de las exportaciones. Las monedas de los principales deudores se han devaluado fuertemente en los últimos dos años. El volumen físico de las exportaciones latinoamericanas aumentó en $8 \%$ entre 1981 y 1983, pero su valor declinó en $10 \%$. El deterioro de los precios de los alimentos y materias primas 
y el proteccionismo en los países centrales, limitan las exportaciones de los deudores y deterioran sus términos de intercambio. Estos últimos se encuentran en el nivel más bajo desde la década de 1930. En tales condiciones, la estrategia ortodoxa no promueve las exportaciones, conforme supone su enfoque del ajuste externo. Sólo logra deprimir los salarios, la producción y el empleo.

En tercer lugar, el superávit comercial y de la cuenta corriente sólo se alcanza mediante la reducción de las importaciones, pero esto es insostenible por más tiempo. Entre 1981 y 1983, las importaciones latinoamericanas se han reducido en más de $40 \%$ y esto afecta, ahora, suministros esenciales de insumos y bienes de capital. Se estima que una caída de importaciones de us\$ 1.000 millones provoca una contracción del PBI de us\$3.000 millones.

El ajuste externo registrado en la América Latina es, en verdad, extraordinario. En 1983, la región pagó intereses y utilidades, neto de nuevos aportes de capital, por us\$30.000 millones. Esto equivale a cerca del $4 \%$ del PBI latinoamericano y el $50 \%$ del ahorro neto de la región. Estas transferencias se financiaron mediante una fuerte compresión de los salarios reales y los niveles de vida.

Contrariamente a lo que suele suponerse, el ajuste externo de la Argentina ha sido más riguroso que en otros países de la región. Entre 1980 y 1983, las importaciones cayeron en $57 \%$ en la Argentina, $50 \%$ en México y $30 \%$ en Brasil. En el trienio 1981-1983, el pago de intereses y utilidades, neto de la entrada neta de capitales, representó el 32\% de las exportaciones argentinas, el $17 \%$ de las brasileñas y el $22 \%$ de las mexicanas. Por otra parte, Argentina entro en el proceso de ajuste después de un prolongado período de estancamiento. El producto por habitante en la Argentina fue, en 1983, $15 \%$ más bajo que en 1970, mientras creció en Brasil (60\%) y México $(30 \%)$, pese a la contracción de los últimos años.

El producto per cápita latinoamericano cayó en $10 \%$ entre 1980 y 1983, el desempleo creció en todas partes y la inflación más que se duplicó. Estos indicadores revelan las tensiones impuestas por un proceso de ajuste que, pese a su intensidad, apenas alcanza para pagar parte de los intereses. La deuda latinoamericana creció en un $20 \%$ entre 1981 y 1983. En particular, el salto de la tasa de inflación se vincula a la dificultad de generar, vía la política fiscal, los excedentes necesarios. Consecuentemente, la inflación se convierte en el instrumento para deprimir los niveles de ingreso real $y$ provocar el superávit buscado en el balance comerciali.

Las razones anteriores explican la inviabilidad del proceso ortodoxo de ajuste. Vale decir, la imposibilidad de generar, a través

Para un análisis de este proceso de ajuste inflacionario en la Argentina, véase, del autor: "La Reforma Financiera, de la Cesación de Pagos a la Argentina Viable". Comercio Exterior, México, noviembre I983. Tambien "Vivir con lo Nuestro". El Gid Editor. Buenos Aires, 1983. 
de las devaluaciones y la depresión continuada del nivel de vida de Ios países deudores, el superávit necesario para pagar los servicios de la deuda.

\section{Los responsables de la crisis}

El escenario actual del endeudamiento latinoamericano incluye, además, un elemento inédito en las finanzas internacionales: el ajuste necesario está indeterminado. A diferencia, por ejemplo, de la situación latinoamericana en la década de 1930, la mayor parte del endeudamiento actual consiste en compromisos de tasa de interés fluctuante. En aquel entonces, la deuda consistía de títulos públicos a tasa de interés fija. Se sabía, pues, cuál era el monto de los servicios. Ahora no; dos tercios de la deuda consiste en préstamos bancarios con tasas ajustables conforme a los cambios del costo internacional del dinero. Las variaciones de la tasa de interés modifican constantemente el servicio de la deuda. Un aumento del $1 \%$ en la tasa de interés representa para la América Latina cerca de us\$3.000 millones. En la Argentina, el monto asciende a us\$300 millones, que equivalen a 2 millones de tn. de trigo, y medido en carne vacuna, al $60 \%$ de las exportaciones actuales. Cualquiera sea la magnitud del esfuerzo, el ajuste está indeterminado y no tiene límite. En tales condiciones, los deudores están subordinados a los vaivenes de la situación internacional y han perdido el control de las principales variables económicas.

La inestabilidad del sistema internacional constituye, así, otro elemento que contribuye a invalidar el esquema ortodoxo de ajuste. La situación emerge del comportamiento del país central del sistema. La economía más rica del mundo y emisora, al mismo tiempo, de la moneda que es el principal activo de reserva internacional, es un factor de perturbaciones del orden mundial contemporáneo. El déficit fiscal de los Estados Unidos asciende a us\$ $\$ 00.000 \mathrm{mi}-$ llones. Esto, más la estrategia de contener la inflación mediante la restricción de la oferta monetaria y el aumento de la tasa de interés, genera una fuerte absorción de fondos desde el resto del sistema financiero internacional y generaliza el aumento de la tasa de interés. Provoca, además, una revaluación del dólar. El dólar se revaluó, respecto de las otras 10 principales monedas, en más del $50 \%$ entre 1980 y principios de 1984. De allí, la pérdida de competitividad de la economía norteamericana, su déficit comercial de US\$100.000 millones y la atracción de capitales del exterior que, según las estimaciones del Presidente de la Reserva Federal, ascenderá en 1984 a us\$ 80.000 millones.

Para los otros países industriales, este comportamiento de la economía norteamericana complica gravemente el manejo de sus propias economías internas pero, al menos, mejora su posición competitiva, incluso dentro del mercado norteamericano. Para los pai- 
ses en desarrollo endeudados, la política norteamericana es una calamidad en toda la líneá. El aumento de la tasa de interés eleva los servicios de la deuda hasta niveles insoportables y la revaluación del dólar deprime los términos de intercambio. La deuda se ha convertido, así, en un factor depresivo y caótico que subordina las políticas nacionales a factores exógenos incontrolables. El dilema que confrontan nuestros países es, pues, si son o no naciones soberanas que deciden su propio destino.

Finalmente, cabe observar que el proceso ortodoxo de ajuste carece de elementos esenciales de equidad que lo justifiquen. Poca duda cabe que los deudores tienen una parte de responsabilidad por las dificultades que enfrentan. Las revaluaciones de las monedas nacionales, la permisividad frente a la transnacionalización de Ios sistemas financieros y otros factores explican, más allá de hechos reales como el aumento de los precios del petróleo, el endeudamiento de algunos países. En otros, como en el Cono Sur; la agresión monetarista y los regímenes autoritarios generaron el peor de los mundos posibles: la destrucción del aparato productivo y empobrecimiento junto a una deuda incurrida por la especulación, el despilfarro, la compra de armamentos y otros desatinos. Pero esto es sólo parte de la historia. Se acaba de ver la responsabilidad en la crisis de la política fiscal y monetaria de los Estados Unidos. Al mismo tiempo, la política de préstamos de la banca acreedora fue más que imprudente en el curso de la década de 1970. Prestaron $\sin$ condicionalidad alguna respecto del destino de los fondos y facilitaron la ejecución de malas políticas o políticas francamente depredatorias en los países deudores. Después de 1981, redujeron drásticamente las corrientes de crédito agudizado, hasta niveles insoportables, el ajuste de los pagos externos. Los bancos prestaron sin límite en la euforia de los años setenta y se retiraron cuando más hacía falta el crédito para facilitar la recomposición de los pagos internacionales. Su comportamiento agrava la inestabilidad del sistema financiero y económico mundial. La opinión pública norteamericana tiene, sobre esta cuestión, una apreciación más realista acerca de la responsabilidad de los bancos que la que impera en otras partes.

En definitiva, la crisis tiene tres responsables: los deudores, los países centrales y los bancos acreedores. Pero el ajute lo están pagando los primeros. No sólo esto. Los acuerdos de refinanciación imponen comisiones y cargos adicionales que han elevado las utilidades de los bancos. En verdad, los deudores deben pagar sus propios errores, pero no pueden hacerse cargo de las consecuencias de las políticas de los países centrales ni de las prácticas de los bancos acreedores. Este elemento de inequidad en el proceso de ajuste inhibe la viabilidad del esquema ortodoxo. 


\section{LA ASIGNAGIÓN DE REGURSOS INTERNOS}

\section{La experiencia tradicional del ajuste externo}

El endeudamiento latinoamericano y las tendencias imperantes en Ia economía internacional han modificado radicalmente el comportamiento de los pagos externos de nuestros países. Tradicionalmente, la América Latina registró un déficit en su balance comercial y, agregado el pago neto al exterior de utilidades e intereses, un déficit aún mayor en la cuenta corriente del balance de pagos. En la década de 1970, el déficit comercial representó el 10\% de las exportaciones totales de la región y el déficit de la cuenta corriente alcanzó al $3 \%$ del P.B.I. latinoamericano. Las entradas netas de capitales financiaron el desequilibrio de lạ cuenta corriente y permitieron, iiiclúso, el incremento de las reservas internacionales.

El caso argentino fue distinto. Tradicionalmente, la Argentina tiene un superávit comercial que excede los pagos al exterior de utilidades e intereses y provoca un superávit de la cuenta corriente. Argentina es normalmente una exportadora neta de capitales medido por la cuenta corriente del balance de pagos. En la década de 1970, el superávit comercial representó el 16\% del valor de las exportaciones y el superávit de la cuenta corriente el 0,1\% del P.B.I. Esto no implica que el pais no haya estado sujeto a la restricción externa. Por el contrario, las oscilaciones dè nivel de actividäd se explican, en gran medida, por las crisis periódicas de los pagos externos. Por otrá parte, el superávit comercial estuvo influido por Ia política restrictiva de importaciones provocado por la insuficiencia de las exportaciones. Esto actuó como un factor limitante de İa! formación de capital y el crecimiento. De todos modos, a diferencia del resto de la América Latina, Argentina ha sido un país exportador de capital en el largo plazo. El problema se agravó, a partir de 1976, bajo el impacto de las polf́ticas monetaristas. En èsta expériencia, la exportación de capitales se financió, en gran parte, con el endeudamiento externo.

\section{Los cambios recientes}

La crisis de la deuda externa provocó modificaciones espectaculares en los pagos externos de la América Latina y, también, en el caso argentino. En 1980 la región experimentó un déficit comercial de us $\$ 7,4$ mil millones y en 1981 de us $\$ 1,6$ mil millones: Producida la crisis, el cambio fue extraordinario. En 1982, se registró un superávit comercial de us $\$ 9.700$ millones y en 1983 de us $\$ 31.200 \mathrm{mi}-$ llones. Este último año, ese superávit representó el $36 \%$ de las exportaciones totales de la región. La incidencia de los pagos de utilidades e intereses convirtió el superávit comercial en un déficit de la cuenta corriente. De todos modos, este declinó de us\$ 40,4 mil 
millones a us $\$ 8,5$ mil millones, entre 1981 y 1983 . La entrada neta de capitales, que tradicionalmente financiaba el déficit comercial y de la cuenta corriente, cayó de us\$38 mil millones a us\$4,5 mil millones entre los mismos años. De este modo, los servicios de la deuda externa y de las inversiones extranjeras radicadas en la región, se pagan ahora con una transferencia real de recursos desde la América Latina al resto del mundo.

En la Argentina el cambio fue igualmente drástico. El superávit comercial pasó de us $\$ 710$ millones en 1981 , a us $\$ 2,7$ mil millones en 1982 y us $\$ 3,9$ mil millones en 1983. La entrada neta de capitales en el trienio cubrió sólo el $40 \%$ de los pagos de intereses y utilidades. La transferencia de recursos al exterior representó en los últimos tres años el 33\% de las exportaciones y el $3 \%$ del P.B.I.

El financiamiento de los pagos internacionales ha cambiado, pues, radicalmente. No se trata, ahora, de sostener una masa-de inversiones externas $y$ endeudamiento cuyos servicios se financian con nuevos aportes de capital, sino de transferir recursos propios. La dimensión de esa transferencia es espectacular y se financió con la disminución del nivel de vida y de la formación interna de capital. Es decir, con más pobreza y el debilitamiento de la capacidad de crecimiento de Iargo plazo.

\section{La cuestión central: la asignación de los recursos propios}

La deuda ha dejado de ser, pues, un problema de financiamiento de Ios pagos internacionales y de movimiento de capitales y pasivos y activos externos. Se ha convertido en una cuestión de utilización de los recursos internos de cada país deudor. Vale decir, en un problema de asignación de los recursos propios entre el pago de Ia deuda y el consumo y la inversión interna. Lo que se debate ahora no es el monto de los capitales externos que permitirian financiar Ios servicios del endeudamiento e, incluso, un déficit del balance comercial y la cuenta corriente, para aumentar los bienes y servicios disponibles por encima de la producción interna. Lo que se discute, es cuántos recursos propios deben destinar los deudores al cumplimiento de sus compromisos externos. La deuda ha sido incorporada como un elemento clave de la asignación de los recursos propios de cada país.

La estrategia de ajuste se refiere a cómo asignar esos recursos y no a cómo financiar con fondos externos los servicios de la deuda. En tales condiciones, desde la perspectiva latinoamericana, actualmente la situación óptima sería que los deudores importen cuanto exporten y los acreedores cobren cuanto presten. Esto revela la naturaleza profunda del problema actual de financiamiento de los pagos externos de nuestros países. Por un buen tiempo, hasta que cambien las tendencias imperantes en el orden mundial, lo que los 
deudores debaten con sus acreedores y el FMr es su propia política económica y la asignación de sus propios recursos. Pocas veces, antes de ahora, ha existido un tan alto grado de ingerencia externa en la definición de Ias políticas económicas nacionales.

No basta, pues, con definir la naturaleza de las políticas de ajuste y si éstas son o no regesivas. Si pagan deprimiendo el nivel de vida y la formación de capital o si, por el contrario, permiten el repunte de la producción, el empleo y el ingreso real. Lo que tenemos que definir es quién decide el rumbo económico y si los países latinoamericanos conservan o no el derecho de decidir su propio destino.

\section{DEUda y ALIENACTóN}

\section{Asignación de recursos propios y autodeterminación}

La deuda, un problema de asignación de recursos propios, ha desplazado su centro de gravedad a los centros financieros internacionales. Los actores principales del debate son los gobiernos de los países deudores, los banqueros acreedores, el FMI y, ocasionalmente, la Tesorería de los Estados Unidos. Los foros habituales en que se debate la asignación de los recursos propios de Ios deudores son Nueva York y Washington. No es extraño que, en tales circunstancias, "los deudores deben" sustituya la aproximación, más realista, de "Ios deudores pueden" pagar hasta tal límite.

Es necesario insistix, pues, en la necesidad de rescatar el centro de gravedad de un problema que se debate en términos de la asignación de los recursos propios de los deudores. En tal sentido, la definición de la política de ajuste debería realizarse entre los principales actores de cada país: sus gobiernos, los trabajadores, empresarios, partidos políticos, es decir, las fuerzas vitales de cada sociedad nacional. El ámbito interno debería ser el marco de referencia central, en el cual cada uno decide qué hace con lo suyo y con su futuro. Los funcionarios con responsabilidad en la política económica evitarían así sus penosas y, frecuentemente, frustrantes peregrinaciones a los centros financieros internacionales. Podrían, entonces, dedicar una atención más intima y profunda a los determinantes internos del desarrollo, del bienestar, de la formación de capital. En verdad, la distribución del tiempo de los funcionarios entre las tratativas financieras internacionales y los problemas domésticos, constituyen un notable ejemplo de pésima asignación de los recursos humanos disponibles. En otros términos, hay que internalizar el problema de la deuda. Si los esquemas recesivos predominan, no es difícil prever que la tensión social y política terminará por internalizar el problema de la deuda, en el peor de los marcos posibles: el caos y las decisiones irreflexivas y rupturistas de las relaciones internacionales. 


\section{Cómo defender la soberania}

La deuda debe ser concebida como un problema importante dentro de la estrategia de desarrollo, distribución del ingreso y ajuste externo. Estas son decisiones indeclinables de cada país, en la medida que pretenda el ejercicio efectivo de su soberanía nacional. ¿Pero es esto posible? ¿Es realmente factible ubicar la deuda en el marco de la política económica de cada país y de sus objetivos nacionales? La respuesta al interrogante requiere atender a dos hechos principales: la disponibilidad de recursos y las relaciones de poder internacional.

Sobre la primera cuestión, cabe observar que todos los deudores están viviendo por debajo de sus propios medios, de sus recursos internos. Replantear el problema de la deuda y limitar el pago de sus servicios a montos compatibles con la movilización de los recursos disponibles y la formación de capital, implica aumentar los recursos disponibles y no reducirlos. En definitiva, de lo que se trata es, por ejemplo, reducir la transferencia de recursos desde la América Latina de los us $\$ 30$ mil millones de 1983 a una cifra sustancialmente menor. Es decir, asumir el cumplimiento de Ios compromisos externos dentro de lo posible. Según mis estimaciones, en el caso argentino no puede destinarse más de un $15 \%$ del valor de las exportaciones al pago de la deuda, si se pretende reactivar la economía y expandir el empleo, el ingreso real y las exportaciones.

Relacionar la capacidad de pagos a un porcentaje de las exportaciones es una propuesta que está ganando adeptos en los países centrales y en América Latina incluso, curiosamente, entre algunos exponentes del pensamiento ortodoxo. La propuesta tiene ventajas. Primero, vincula el esfuerzo del país deudor al comportamiento del mercado mundial y al resultado de las políticas de los países centrales del sistema. Segundo, prolonga los plazos de amortización cada vez que el aumento de las tasas de interés en los centros financieros internacionales eleva los servicios de la deuda. Estas son dos vías efectivas de compartir el costo del ajuste entre los deudores, los bancos y los países centrales.

En el caso argentino, limitar los pagos de intereses al $15 \%$ de las exportaciones reduciría la transferencia de recursos internos a alrededor de Us\$ 1.500 millones. Es decir, liberaría recursos propios para la inversión y el consumo internos. En la América Latina, la limitación del pago de irntereses al $15 \%$ de los ingresos de exportaciones, reduciría la transferencia de recursos de us\$30.000 millones (registrado en 1983) a us\$ 15.000 millones. La diferencia representa el $2 \%$ del PBI latinoamericano y el $20 \%$ del ahorro neto de la región. En los pagos con recursos propios debería darse prioridad a la deuda comercial, para mantener la fluidez de las corrientes de comercio y su financiamiento. La deuda de origen financiero 
puede quedar sujeta a los programas de rescalonamiento de los servicios.

¿Es esto fáctible dadas las relaciones de poder internacional? Dos razones principales inducen a una respuesta positiva de este interrogante. Primero, el carácter global de los problemas internacionales y el convencimiento creciente en la comunidad financiera y en los medios políticos de los países centrales, que la deuda latinoamericana no tiene solución dentro de los carriles tradicionales del ajuste. La vulnerabilidad de lö bancos acreedores por el grado de exposición frente a sus deudores, la responsabilidad que comparten en la generación de la crisis y el papel de la política fiscal y monetaria norteamericana en el actual desorden de la economía mundial, revela la debilidad de los centros de poder para presionar a los deudores más allá de un cierto punto. El acuerdo del 30 de marzo último, para saldar los atrasos argentinos en el pago de intereses de la deuda, revela que, en definitiva, se encuentran fórmulas heterodoxas para resolver las situaciones de hecho. Como minguno de los deudores plantea el repudio de la deuda, sino su rescalonamiento en términos compatibles con la capacidad de pagos externos, es improbable que los acreedores conviertan en juicios y embargos, créditos que, en definitiva y de algún modo, serán refinanciados. No es creíble Ia tesis apocalíptica del aislamiento internacional de los deudores que afirmen su derecho a la soberanía y a la autodeterminación y. que manterigan el compromiso de ir pagando sus obligaciones. En definitiva, los mismos centros de poder internacional están interesados en que el actual desorden del sistema económico y financiero internacional no termine con las reglas del juego que sostiene el orden económico y la seguridad de Occidente. En situaciones límite, los acreedores revelan poca vocación al adoptar actitudes irreconciliables con los países deudores. Se confronta, pues, un contexto externo fluido en que existe una considerable capacidad de maniobra para los deudores. Segundo, el hecho que, por estar los principales deudores viviendo dentro de sus propios medios, no es posible presionarlos mediante la amenaza de cortar suministros esenciales para su desenvolvimiento. Esto es particularmente evidente en el caso argentino. Un país con excedentes de alimentos, cercano al autoabastecimiento energético y con un sustancial superávit comercial vive, en efecto, con lo suyo. A la Argentina no se le pueden cortar los víveres. Vivimos con lo nuestro. El consumo y la inversión interna son inferiores al PBI.

En definitiva, es necesario y factible ubicar el problema de la deuda en el marco de las estrategias nacionales de desarrollo, distribución del ingreso y ajuste externo. Es posible e indispensable eliminar la actual alienación del problema de la deuda. Además, esta es la única manera de evitar la cesación de pagos y mayores perturbaciones en las relaciones económicas internacionales. La vía 
más segura a la cesación de pagos es la insistencia en las estrategias ortodoxas de ajuste.

\section{LA CRISIS IATTINOAMERIGANA}

\section{La situación preexistente}

¿Por qué, entonces, esta alienación en el tratamiento de la deuda externa? Siendo ésta un problema de asignación de recursos internos, ¿qué razones explican el fenómeno? Si el contexto internacional puede absorber políticas responsables y nacionalistas de los deudores: ¿por qué tanto pánico frente a una eventual e inviable sanción desde Ios centros de poder internacional? ¿Qué impide que los deudores internalicen el problema de la deuda, determinen el monto del esfuerzo máximo posible y reasuman el comando de sus economías nacionales?

Las respuestas exceden el ámbito del análisis económico. Las variables económicas explican apenas una parte del comportamiento de los países deudores. La deuda vino a desnudar tensiones profundas de las sociedades nacionales y de los modelos prevalecientes de desarrollo. Con o sin deuda externa, la acumulación de capital con concentración del ingreso, prevalecientes en Brasil y México durante toda la fase expansiva de los últimos lustros, dejaron de ser viables. No parece posible seguir sosteniendo fuertes tasas de crecimiento asentadas en la concentración del ingreso y en la marginación de amplios sectores sociales de los frutos del desarrollo. La hipertrofia del Estado y el desborde del poder burocrático, los obstáculos a la actividad creadora de la iniciativa privada, la ausencia de respuestas eficaces a las necesidades sociales más urgentes, mientras se despilfarran los recursos en consumo suntuarios y en la fuga de capitales, son pautas de comportamiento incompatibles. con un desarrollo autosustentado y el equilibrio externo. La deuda es un aspecto de la crisis de tales modelos de desarrollo, pero sólo uno. Está en tela de juicio todo el proceso de acumulación, de cambio tecnológico, de integración de las economias regionales, de participación del sector público en el proceso económico. El cuestionamiento abarca los modelos de articulación social y política de cada sociedad nacional. Se advierten, así, reclamos de participación, la afirmación de libertad como valor esencial de nuestra cultura, el rechazo de las manipulaciones que sirven a intereses sectarios $y$ comprometen los de la nación.

En la Argentina, la calamidad monetarista había estallado antes que la crisis de la deuda emergiera en el escenario internacional. La economía nacional fue sometida a un proceso de achicamiento, despojo y empobrecimiento, del que no existen precedentes en el país ni en América Latina. El derrumbe del sistema político autoritario era manifiesto antes de la crisis de la deuda e, incluso, antes 
del conflicto de Malvinas. EI país estaba buscando ya el camino de la reparación institucional y las soluciones a la profunda crisis económica y social desencadenạda por la agresión monetarista.

Con o sin deuda externa, con o sin FMrI, las sociedades latinoamericanas enfrentan dificultades profundas y la necesidad de cambios en su organización económica y social, en sus modelos de acumulación y crecimiento, en las vías de su inserción internacional.

\section{El mecanismo de negación y desplazamiento}

No es extraño que, en tales condiciones, la deuda externa se haya convertido en un mecanismo de negación de los problemas internos de las sociedades nacionales y refleje la debilidad para enfrentar las transformaciones internas impostergables. Vivimos un mundo paradojal. Un mundo en que el marco externo influye profundamente en el comportamiento de cada sociedad nacional. $X$, sin embargo, son Ios problemas internos, las pautas culturales de cada pueblo, sus sistemas políticos, las aspiraciones y conflictualidad domésticas, las que actúan como factores dominantes del comportamiento de cada país. La deuda externa ha venido a trastocar este anclaje interno de los problemas esenciales de nuestros países y lo ha desplazado al escenario de las negociaciones financieras internacionales, donde ningún problema, incluyendo la deuda, puede encontrar actualmente solución.

El mecanismo de negación y desplazamiento del centro de gravedad del adentro al afuera, también funcionó en los años prósperos de las décadas del 60 y 70. Algunos gobiernos latinoamericanos mantuvieron posiciones críticas y combativas en procura de un nuevo orden económico internacional. Sin embargo, revelaron una considerable incapacidad de realizar transformaciones internas que satisfacieran, siquiera en parte, sus propios reclamos dentro del sistema mundial. Desplazaron al afuera los obstáculos internos al cambio.

Con o sin deuda externa, con o sin FMI, es indispensable ordenar al Estado y equilibrar el presupuesto, rediștribuir el ingreso, realizar profundas reformas fiscales, reorganizar los sistemas financieros, frenar la inflación y ajustar los pagos internacionales. Como en todas partes, estos son desafíos complejos que conmueven la organización política de cada sociedad. Europa, después de la Segunda Guerra Mundial, reveló la energía política necesaria para realizar reformas monetarias que eliminaron de raíz las bases del desequilibrio fiscal y la inflación. Reveló, también, la capacidad de establecer compromisos políticos internos que transaran, durante toda la fase de reconstrucción y despegue, las pujas por la distribución del ingreso. $Y$, además, la capacidad administrativa para tener bajo severo control los pagos internacionales hasta que se recuperaron las reservas y la capacidad exportadora. Es cierto, que 
el comportamiento de los Estados Unidos contribuyó a esos fines, pero esto hubiera sido insuficiente sin el esfuerzo interno.

Esto no se observa hoy en día en nuestros países. No se advierten reformas fiscales y monetarias profundas para enfrentar la crisis, para transar la puja distributiva y permitir la expansión del gasto y el ingreso real sin inflación, para atender a los reclamos más urgentes de nuestros pueblos. Esta debilidad para enfrentar los problemas reales, aparece ahora enmascarada tras el problema de la deuda y su desplazamiento al foro de las negociaciones internacionales, donde no existe solución efectiva al problema. Porque, en las condiciones actuales, la deuda es, esencialmente, un problema de asignación de recursos internos entre el pago de intereses y el consumo y la inversión interna. Este desplazamiento del centro de gravedad de la deuda hace suponer la existencia en el afuera, de restricciones irreales $y$, también, de rigideces en las posturas negociadoras de los acreedores que, en verdad, podrían ser modificadas con una actitud distinta de los deudores.

Desde la crisis de los años treinta y, particularmente, durante toda la fase de sustitución de importaciones, después de la Segunda Guerra Mundial, los principales países latinoamericanos realizaron considerables progresos en desmontar los viejos mecanismos del atraso. Se superó, en parte, la tradicional dependencia de las exportaciones primarias, avanzó en la integración de los perfiles industriales y el espacio territorial, incorporaron áreas productivas en la vanguardia tecnológica, capacitaron los recursos humanos y fortaleciéronse las políticas de administración de recursos. El crecimiento del producto, del ahorro interno y del peso relativo de la industria; la creciente productividad de la actividad primaria y la formación de nuevos sectores sociales ligados a las áreas en expansión, revelan la profundidad de los cambios producidos en la región y el desmantelamiento de viejas estructuras del atraso y la dependencia. Es cierto que surgieron nuevos problemas y aparecieron nuevos obstácuIos que frustraron, en parte, la autonomía en la administración de las políticas nacionales. Pero la ruptura del sistema multilateral de comercio y pagos a partir de la crisis de los años treinta y las consecuencias de la Segunda Guerra Mundial, independizaron, en buena medida, las políticas fiscales y monetarias de las viejas ataduras del patrón oro. Nuestros países no superaron, en el último medio siglo, las raíces profundas del atraso y la pobreza, pero multiplicaron su capacidad de producción, ahorro y acumulación de capital. Los recursos reales disponibles hoy en día configuran un cuadro distinto al de hace tres o cuatro décadas. Los principales países del área cuentan hoy con los medios necesarios para enfrentar la crisis y afirmar modelos de desarrollo de capacidad expansiva y reparadora de los más urgentes problemas sociales. ¿Por qué no lo hacen y están atrapados en los dilemas insolubles de la deuda?

Guando gobiernan las minorías, en el marco de regímenes auto- 
ritarios; se comprende que no exista vocación alguna de promover el crecimiento y la redistribución progresiva del poder y el ingreso. En tales casos, la receta ortodoxa es el camino indicado para consolidar la situación prevaleciente. La deuda externa es un argumento excelente para justificar su aplicación.

La transformación en el marco de la democracia es una tarea más compleja. Implica concertar acciones en sociedades pluralistas, de débiles tradiciones democráticas y agobiadas por las mismas tensiones sociales del atraso. De allí, la debilidad que suele advertirse en gobiernos democráticos para operar con la energia y eficacia requeridas. De allí, también, el desplazamiento hacia el contexto externo de las causas y la resolución de la crisis.

\section{Las amenazas al derecho de autodeterminación}

Pero este mecanismo de negación y desplazamiento del centro de gravedad de la deuda desde el adentro hacia el afuera, es extremadamente peligroso. Nuestros países quedaron atrapados en la expansión, hipertrofia y transnacionalización del sistema financiero internacional.. Hoy, la deucla presenta tales características que constituye una grave amenaza a las soberanías nacionales y al derecho de autodeterminación de nuestros pueblos. Por qué no se trata, como en las décadas de 1950 y 1960 , de aplicar programas transitorios de ajuste que, en el corto plazo, restablecerán el equilibrio de los pagos internacionales. $\mathrm{El}$ tema de la deuda seguirá pendiente largo tiempo y estamos comprometiendo toda la política económica por plazos indefinidos, es decir, está en juego el destino nacional de nuestros países.

El mecanismo de negación posterga la solución de los problemas y, por esto mismo, los agrava con la profundización del receso, del desempléo y de la pobreza de sectores fundamentales de nuestras sociedades. ¿Hasta cuándo podremos seguir negando estas realidades y discutiendo en Nueva York, Washington 'o París, las políticas a seguir y trasladar a esos foros responsabilidades que son esencialmente nuestras? Estamos en presencia de otro de los círculos viciosos típicos del atraso. Como es difícil poner en orden la situación interna, vamos a la negociación internacional en las peores condiciones posibles. Los programas que reducen grandemente los recursos propios disponibles, complican aún más los problemas internos de base. No puede seguirse mucho tiempo más en este esquema.

El problema principal de la deuda no lo plantean hoy los banqueros ni el F.M.I. Lo plantea la dificultad de asumir los problemas tal cual son. La incorporación de la deuda dentro de las estrategias nacionales de desarrollo, distribucion y ajuste externo, puede provocar tensiones más o menos severas con la comunidad financiera internacional. Pero el riesgo de incurrir en atrasos, para no continuar deprimiendo las economías nacionales, es mucho menor que 
el peligro de seguir agudizando las tensiones sociales y políticas. Esto último es más riesgoso, incluso, para los acreedores.

\section{Democracia y soberania}

La única respuesta realista consiste en perfeccionar los mecanismos de acción de la democracia y, en este contexto, incorporar la deuda como un problema central, pero sólo uno de los desafíos que confrontan nuestros países. No será posible recuperar el derecho a la libertad y la autodeterminación sin realizar los cambios internos indispensables ${ }^{2}$.

El contexto internacional es suficientemente flexible para absorber planteos responsables y nacionalistas de los deudores. La convicción ortodoxa se está desmoronando en los centros de poder internacional e, incluso, en la comunidad financiera internacional. Si no se encuentran en el ámbito mundial respuestas globales es por la propia inercia de los acontecimientos y las dificultades de los países centrales de resolver los principales dilemas de la economía mundial. No es concebible que políticas de "vivir con lo nuestro", limiten el pago de la deuda a lo posible y documenten el resto, con valores a mediano y largo plazo, den lugar a rupturas de las relaciones internacionales. Por el contrario los países centrales y la banca internacional serían inducidos a admitir la realidad de los hechos y proceder en consecuencia. Pero, mientras nuestros países sigan negando la esencia profunda de sus conflictos y problemas, no puede esperarse sino que los banqueros, el FiMI y los otros actores del mundo desarrollado, continúen apegados a los esquemas tradicionales. En verdad, las voces críticas a los esquemas ortodoxos de ajuste, son más audaces y realistas en los países clesarrollados que en la América Latina. Si las reglas del juego internacional no cambian es, en gran medida, porque los deudores no asumen sus responsabilidades de un desarrollo basado en los propios recursos y el potencial interno. No se trata de seguir políticas autarquistas, sino de centrar los modelos de desarrollo en las realidades $y$ posibilidades internas de cada país. En este contexto, la dimensión latinoamericana y la cooperación entre nuestros países en el tema de la deuda y en otras áreas, adquiere un importante papel transformador's.

Estos dilemas son esenciales para el proceso de democratización que se está expandiendo por la América Latina. Las minorías están

\footnotetext{
3Para enfoques alternativos a las estrategias ortodoxas de ajuste, puede verse, para Brasil: C. Furtado: Nao a recessao e ao desemprego, Paz e Terra. Río, 1983 y R. Dornbusch: A stabilisation program for Brazil, (mimeo), 1983. Para el caso argentino, véase del autor: Vivir con lo nuéstro, ob. cit.

${ }^{3}$ A. Ferrer: La deuda externa y la conveniencia latina e iberoamericana. Ponencia presentada al Séptimo Congreso Mundial de la Asociación Internacional de Economia, Madrid, septiembre de 1983. Reproducido en Comercio Exterior, México, diciembre de 1983.
} 
apegadas a los esquemas ortodoxos, aunque no existieran la deuda externa, los acreedores ni el IrMI. Esto es particularmente evidente en el caso argentino, donde las viejas élites del sistema preindustrial y de la especulación financiera, aspiran a retrotraer al país al sistema prevaleciente antes de 1930 y a subordinar el aparato productivo a la función financiera. Para estos sectores, la deuda constituye un espléndido argumento para insistir en la imposibilidad de una política nacional independiente y reclamar la subordinación para sobrevivir y evitar el colapso. De allí la tentativa, considerablemente exitosa, de aterrorizar al país con amenazas de embargos, bloqueos, desabastecimientos y otras calamidades que resultarían de no firmar lisa y llanamente donde impongan los acreedores. Pero, en definitiva, el problema radica en la propia debilidad de las fuerzas nacionales para plantear los problemas en sus bases reales y aprovechar el formidable potencial transformador de la democracia. Para afianzar la unión en torno de objetivos esenciales a la nación y a su derecho irrenunciable a la libertad, el desarrollo y la autodeterminación. En definitiva, de la superación de estas debilidades dentro de las mayorías nacionales y de la formulación de programas realistas de ajuste y desarrollo, dependerá que la deuda pueda pagarse sin sacrificar nuestro futuro. 